\section{BRAZIULIAN JOURNAL}

OF MEDICAL AND BIOLOGICAL RESFARCH

www.bjournal.com.br
ISSN 0100-879X

Volume 43 (5) 381-496 May 2011

BIOMEDICAL SCIENCES

AND

CLINICAL INVESTIGATION

Braz J Med Biol Res, May 2011, Volume 44(5) 460-468

doi: 10.1590/S0100-879X2011007500040

Short-term exposure of mice to cigarette smoke and/or residual oil fly ash produces proximal airspace enlargements and airway epithelium remodeling

P.J.C. Biselli, F.D.T.Q.S. Lopes, H.T. Moriya, D.H.R.F. Rivero, A.C. Toledo, P.H.N. Saldiva,

T. Mauad and M.A. Martins

The Brazilian Journal of Medical and Biological Research is partially financed by

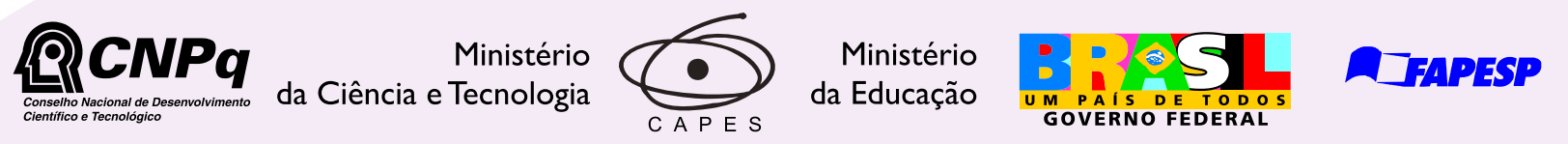

Institutional Sponsors
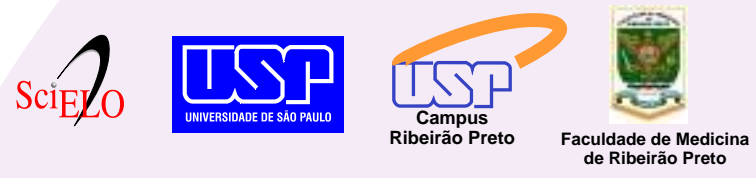
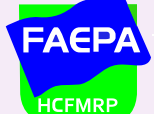

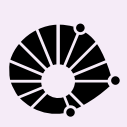

Ф SHIMADZU

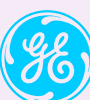

GE Healthcare
Hotsite of proteomics metabolomics developped by:

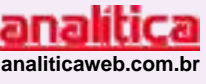

Thermo SCIENTIFIC 


\title{
Short-term exposure of mice to cigarette smoke and/or residual oil fly ash produces proximal airspace enlargements and airway epithelium remodeling
}

\author{
P.J.C. Biselli ${ }^{1}$, F.D.T.Q.S. Lopes ${ }^{1}$, H.T. Moriya ${ }^{3}$, D.H.R.F. Rivero ${ }^{2}$, \\ A.C. Toledo ${ }^{1}$, P.H.N. Saldiva ${ }^{2}$, T. Mauad ${ }^{2}$ and M.A. Martins ${ }^{1}$ \\ ${ }^{1}$ Departamento de Clínica Médica (LIM 20), ²Laboratório de Poluição Atmosférica (LIM 5), \\ Departamento de Patologia, Faculdade de Medicina, Universidade de São Paulo, São Paulo, SP, Brasil \\ ${ }^{3}$ Laboratório de Engenharia Biomédica, Escola Politécnica, Universidade de São Paulo, São Paulo, SP, Brasil
}

\begin{abstract}
Chronic obstructive pulmonary disease (COPD) is associated with inflammatory cell reactions, tissue destruction and lung remodeling. Many signaling pathways for these phenomena are still to be identified. We developed a mouse model of COPD to evaluate some pathophysiological mechanisms acting during the initial stage of the disease. Forty-seven 6- to 8-week-old female C57/BL6 mice (approximately $22 \mathrm{~g}$ ) were exposed for 2 months to cigarette smoke and/or residual oil fly ash (ROFA), a concentrate of air pollution. We measured lung mechanics, airspace enlargement, airway wall thickness, epithelial cell profile, elastic and collagen fiber deposition, and by immunohistochemistry transforming growth factor- $\beta 1$ (TGF- $\beta 1$ ), macrophage elastase (MMP12), neutrophils and macrophages. We observed regional airspace enlargements near terminal bronchioles associated with the exposure to smoke or ROFA. There were also increases in airway resistance and thickening of airway walls in animals exposed to smoke. In the epithelium, we noted a decrease in the ciliated cell area of animals exposed to smoke and an increase in the total cell area associated with exposure to both smoke and ROFA. There was also an increase in the expression of TGF- $\beta 1$ both in the airways and parenchyma of animals exposed to smoke. However, we could not detect inflammatory cell recruitment, increases in MMP12 or elastic and collagen fiber deposition. After 2 months of exposure to cigarette smoke and/or ROFA, mice developed regional airspace enlargements and airway epithelium remodeling, although no inflammation or increases in fiber deposition were detected. Some of these phenomena may have been mediated by TGF- $\beta 1$.
\end{abstract}

Key words: Emphysema; Cigarette smoke; Airways; TGF- $\beta 1$; Mouse airway epithelium remodeling; Proximal airspace enlargements

\section{Introduction}

Chronic obstructive pulmonary disease (COPD) is an inflammatory disease involving partially reversible air flow obstruction. The most important risk factor for the disease is exposure to cigarette smoke. Environmental pollution may also contribute to the development of the disease, although its contribution is much smaller than that of cigarette smoke (1). Both factors may interact, contributing to disease progression due to the fact that environmental pollution seems to be particularly hazardous to individuals already at risk for lung or heart disease $(2,3)$ and to lungs already injuried by other factors (4).

The pathophysiology of COPD has been extensively studied over the last few years and the importance of inflammatory cells for disease progression is recognized. These cells are present in many individuals with COPD and are required for the development of emphysema (5-7). However, other mechanisms participating in the development of the disease such as oxidative stress (8), lung cell apoptosis (9-11), cytokine signaling $(5,12,13)$, and extracellular matrix proteases (5) have also been identified. The contribution of each of these mechanisms and their relation to the inflammatory response are being clarified, but there are still many features remaining to be understood.

Experimental models have shown that, usually, 6

Correspondence: P.J.C. Biselli, Departamento de Clínica Médica (LIM 20), Faculdade de Medicina, USP, Av. Dr. Arnaldo, 455, 01246-903 São Paulo, SP, Brasil. Fax: +55-11-3085-0992. E-mail: paolobiselli@usp.br

Received July 12, 2010. Accepted March 10, 2011. Available online April 1, 2011. Published May 16, 2011. 
months of exposure to cigarette smoke are required before emphysema can be detected in mice $(6,7,14-17)$. While some investigators have described inflammatory reaction and cytokine production right after smoke exposure, this response seems to diminish over time and to change substantially after several months of continued exposure to smoke (18-20). Many studies have been conducted aiming to describe COPD mechanisms in animals after emphysema is completely established (6,7,14-17). Little research, however, has been carried out in an earlier phase of emphysema formation, when some mechanisms that will eventually lead to parenchyma destruction may have been already triggered $(17,18,20)$. Therefore, studying animals after the initial phase of smoke exposure, but before emphysema has been completely established, can provide clues to some pathogenic mechanisms at a stage where the disease may have a greater possibility of being reversed.

Today, environmental pollution is a growing problem that will continue to affect a large number of individuals in the next years. Environmental pollution can exacerbate the symptoms of $\operatorname{COPD}(2,3)$, resulting in more hospital admissions. Despite this positive epidemiological association, there are still few experimental data evaluating the interaction between smoke and environmental pollution in COPD.

Residual oil fly ash (ROFA) is a suspension of the material produced after oil burning, which has been used in some experimental models to standardize the exposure protocol $(21,22)$. Once its components can be identified, and the material can be stored for several years, the experimental protocol can be repeated in a more standard manner, thus being suitable for a model trying to uncover responses elicited by some contents of air pollution. Although ROFA exposure does not exactly mimic environmental pollution, we have chosen to use it since it contains high concentrations

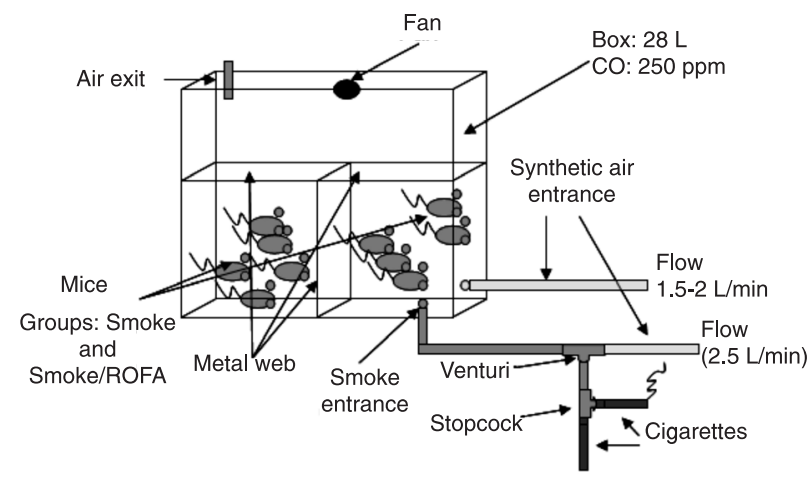

Figure 1. Schematic representation of the smoke exposure chamber. Animals in the groups Smoke and Smoke/residual oil fly ash (ROFA) were maintained in this 28-L plastic box for $2 \mathrm{~h}$ a day, 5 days a week for 2 months. The $\mathrm{CO}$ concentration inside the box was maintained from 250 to 350 ppm by controlling the smoke flow entrance to the box. of many components of air pollution and could produce a stronger and less variable response.

We have planned an experimental study to evaluate the development of emphysema in mice after a chronic but short-term exposure to cigarette smoke (2 months), combined with exposure to a concentrate of air pollution. Our objectives were to search for emphysema formation at an earlier stage, to evaluate possible disease mechanisms activated in this phase of the process and to explore the interaction between these two noxious factors.

\section{Material and Methods}

The study was approved by the institutional review board of Hospital das Clínicas, University of São Paulo, Brazil. All animals received care in compliance with the "Principles of Laboratory Animal Care" published by the National Institutes of Health (23).

\section{Experimental groups}

Forty-seven 6- to 8-week-old female C57/BL6 mice were divided into 4 groups according to the exposure protocol: a) mice that received intranasal instillation of $0.9 \% \mathrm{NaCl}$ (Saline; $N=13$ ); b) mice that received intranasal instillation of ROFA (ROFA; $N=10$ ); c) mice that were exposed to cigarette smoke (Smoke; $N=11$ ), and d) mice that received intranasal instillation of ROFA and were exposed to cigarette smoke (Smoke/ROFA; N = 13).

\section{Exposure to ROFA}

Animals in the ROFA and Smoke/ROFA groups received the nasal administration of $10 \mu \mathrm{L}$ of a $5 \mathrm{mg} / \mathrm{mL}$ suspension of ROFA, a concentrate of solid pollutants resulting from the burning of oil in a hospital boiler, 5 days a week for two months. Animals from the other two groups (Saline and Smoke) received nasal administration of $10 \mu \mathrm{L}$ saline, the vehicle of the ROFA suspension, for the same period of time. The composition of ROFA was described elsewhere (21).

\section{Exposure to cigarette smoke}

Animals in the Smoke and Smoke/ROFA groups were exposed to cigarette smoke in a 28-L plastic box (Figure 1) with two inlets, one for smoke and one air, and an outlet. Through the first inlet we applied a 2-L/min flow of synthetic air and through the second inlet we applied a synthetic air flow that could be regulated by a flowmeter and that passed through a Venturi T-piece connected to a lit cigarette. This system suctioned the cigarette smoke and led it to the box in which the carbon monoxide concentration was monitored during the initial experiments (ToxiPro, Biosystems, USA). After some measurements, the flow through the second inlet was set at $2.5 \mathrm{~L} / \mathrm{min}$, which produced CO concentrations ranging from 250 to $350 \mathrm{ppm}$ inside the box. We used approximately 45 cigarettes per day to produce this $\mathrm{CO}$ concentration for $2 \mathrm{~h}$ in the box. The concentration of car- 
boxyhemoglobin was $23 \%$, and was measured in a separate experiment based on the same exposure protocol.

Animals were kept in the smoking box for $2 \mathrm{~h}, 5$ days a week for 2 months. Animals from the other groups (ROFA and Saline) remained in their cages during the smoke exposure protocol.

\section{Mechanical ventilation}

After 2 months, animals were anesthetized with thiopental $(250 \mathrm{mg} / \mathrm{kg})$, tracheotomized, and connected to a ventilator for small animals (flexiVent, Scireq, Canada). Data were obtained using a forced oscillation technique after animals had been paralyzed with pancuronium (0.2 $\mathrm{mg} / \mathrm{kg}$ ). According to a previously described model (24), respiratory mechanics were characterized by the following parameters: airway resistance (Raw), tissue damping (Gtis) and tissue elastance (Htis).

\section{Lung morphometry and immunohistochemistry}

After the lung mechanics procedure, animals were killed by exsanguination and their lungs were removed and fixed in $10 \%$ buffered formalin for $24 \mathrm{~h}$ at a constant pressure of 20 $\mathrm{cmH}_{2} \mathrm{O}$. The lungs were then cut and paraffin embedded and $5-\mu \mathrm{m}$ sections were prepared for histological analysis.

Sections were stained with hematoxylin-eosin, Sirius red (for collagen fiber detection), resorcin-fuchsin (for elastic fiber detection) and periodic acid Schiff and Alcian blue (for epithelial cell analysis).

For immunohistochemical analysis, sections were deparaffinized and hydrated, endogenous peroxidase was blocked and antigen was retrieved with trypsin or high temperature. The following primary antibodies were used: anti-Mac2 (1:25,000, Clone M3/M38 Cedarlane Lab., Canada), rat anti-mouse neutrophils (1:400, Abd Serotec, UK), goat polyclonal anti-mouse MMP12 (1:200, Santa Cruz Biotechnology, USA), and rabbit polyclonal antitransforming growth factor- $\beta 1$ (TGF- $\beta 1$ ) IgG (1:1200, Santa Cruz Biotechnology, USA). Anti-goat, rat or rabbit antibodies (Vectastain Abc Kit, Vector Laboratories, USA) were used as secondary antibodies. Sections were counterstained with hematoxylin. Controls were performed using BSA in substitution for primary antibodies.

\section{Airspace enlargement}

To measure airspace distension, sections were placed on a light microscope (Zeiss, Germany) adapted to a video camera (Samsung, South Korea) with magnification of 390 times. The images were displayed on a monitor, where a frame of 5 concentric semicircles was placed. After correction for the magnification of the optic system, the radiuses of the 5 semicircles were $50,100,150,200$, and $250 \mu \mathrm{m}$. The frame was attached to the monitor screen in such a way that the center of the semicircles was placed on a terminal bronchiole, allowing the semicircle lines to lie over the lung parenchyma. The length of each of the
5 semicircles was divided by the number of intersections between the line and lung tissue. Ten different fields per slide were analyzed, producing one measurement of the degree of airspace enlargement at each of the 5 different distances from the terminal bronchiole.

\section{Inflammatory cells}

Neutrophil, macrophage and macrophage elastase (MMP12)-positive cell infiltration was evaluated in two different lung regions, i.e., parenchyma and bronchovascular space - a region of soft tissue around the bronchioles and vessels. We analyzed 10 fields of parenchyma and 5 bronchovascular space regions per slide. The analysis of lung parenchyma was performed by counting the number of cells and dividing it by the tissue area present in the same visual field. Tissue area was obtained by point counting or by thresholding a photomicrograph into tissue and non-tissue regions, determining the tissue relative area with the use of the ImageJ software (NIH, USA).

\section{Elastic and collagen fiber analyses}

Sections stained with Sirius red (for collagen fibers) and resorcin-fuchsin (for elastic fibers) were evaluated in the parenchyma region and in the airways. We photographed 10 parenchyma fields and 5 airways per slide. The proportion of the area occupied by each type of fiber divided by the tissue area or by the airway basement membrane perimeter was calculated for comparisons among groups.

\section{Airway thickening and epithelial cells}

Airway thickening was measured by photographing 5 airways per slide and calculating airway areas divided by their length, which was measured by drawing a line parallel to the airways basement membrane. For this analysis, we used the Image J Software (NIH, USA). Epithelial cells were analyzed with a light microscope (Olympus, Japan) with 1000X magnification. By point counting, we determined the volume proportion of all epithelial cells, which were further classified according to the following features: ciliated cells, mucous cells and non-ciliated-non-mucous cells.

\section{TGF- $\beta 1$ analyses}

Ten fields of parenchyma and 5 airways were photographed per slide. The stained area was calculated using the Image J software, and divided by the tissue area. The process was performed in airways and lung parenchyma, as described above.

\section{Statistical analysis}

For parametric data, we used two-way ANOVA for multiple group comparisons. This test uses a general linear model to identity one factor (ROFAor smoke) associated with a certain effect. It does not compare one group to the others directly. For non-parametric data (analyses of epithelial cell profile), we used the Kruskal-Wallis test. We considered P 
values less than 0.05 as statistically significant. Analyses were performed using the SigmaStat software (Aspire, USA).

\section{Results}

Examples of photomicrographs of lung parenchyma and airways of all four groups are shown in Figure 2. Although it is hard to note differences in airspace enlargements, it is possible to observe an increase in airway wall thickness, which was detected by quantitative methods.

The results of Raw assessed by oscillatory lung mechanics are presented in Figure 3. Data were $\log _{10}$ transformed to smooth dispersion, allowing parametric analysis. Increased Raw values were observed in animals exposed to smoke (ROFA/Smoke and Smoke groups) compared to control animals and animals exposed only to ROFA ( $P$ $=0.01$ ). There were no statistically significant differences among the 4 groups in the remaining parameters, i.e., Gtis and Htis.

We did not detect any statistically significant differences in the densities of neutrophils, macrophages or MMP12-positive cells in lung parenchyma or bronchovascular spaces, in animals exposed to ROFA or smoke.

Figure 4 shows the results of airspace distension measured at different distances from a terminal bronchiole. There were no differences among the 4 groups at 50 , 200 and $250 \mu \mathrm{m}$ from the airways. However, an enlargement of airspaces was detected at $100 \mu \mathrm{m}$ in animals exposed to smoke (two-way ANOVA, $P=0.034$ for factor smoke). The difference seemed to be greater in the group exposed to both ROFA and smoke. An increase in the airspaces was also noted at 150 $\mu \mathrm{m}$ from the airways in the animals exposed to ROFA(two-wayANOVA, $P=0.006$ for the factor ROFA).

There were no statistically significant differences among groups in the volume proportion of elastic or collagen fibers in the lung paren- chyma or in the airways.

Airway analyses are presented in Figures 5 and 6. An increase in wall area corrected by its length was observed in animals exposed to smoke $(P=0.006)$. The analysis of the
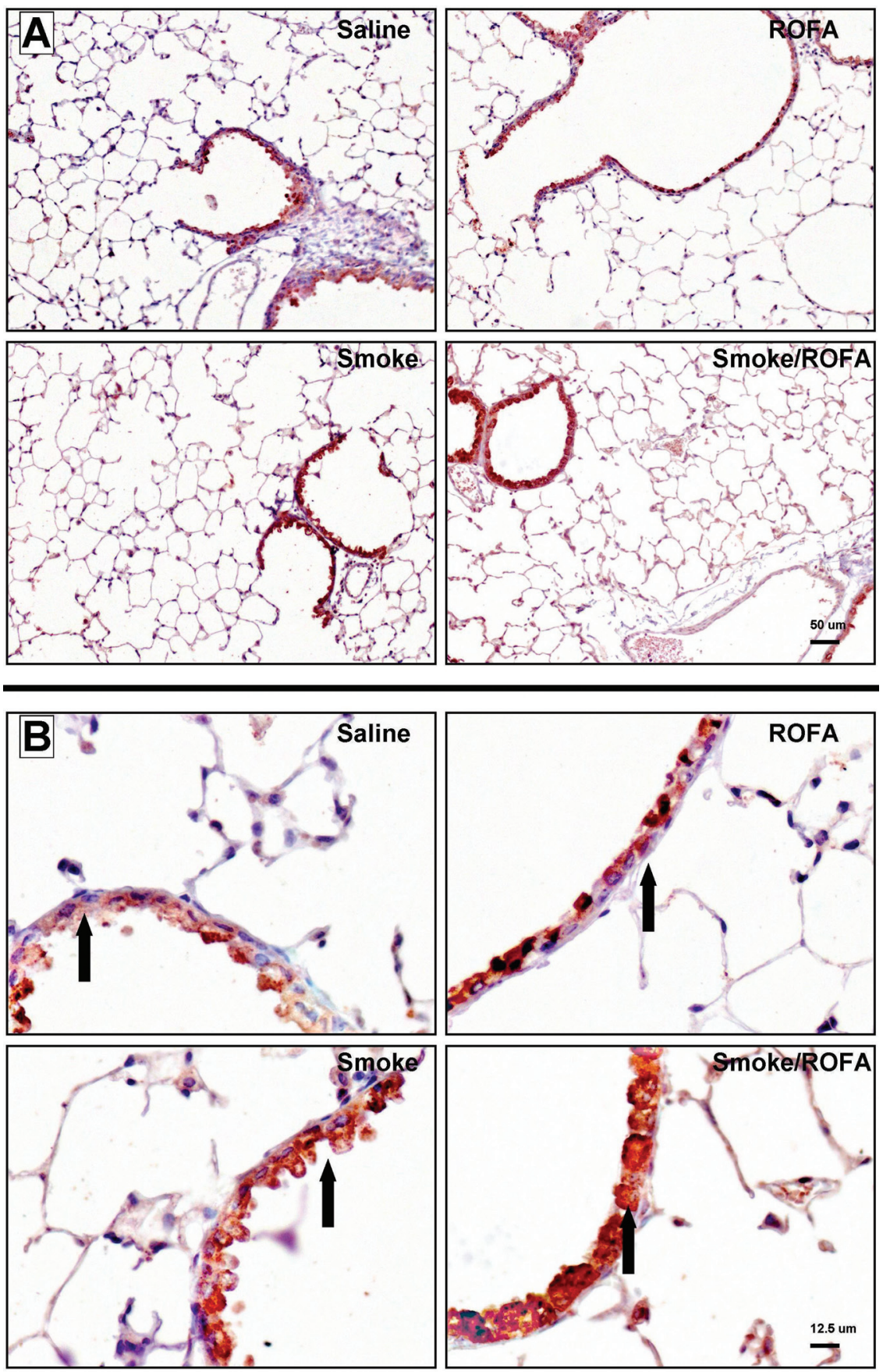

Figure 2. The photomicrographs show selected lung sections from each group, stained for transforming growth factor- $\beta 1$ (TGF- $\beta 1$ ) at $400 \mathrm{X}$ magnification (Figure 2A) and 1600X magnification (Figure 2B). Although it is very difficult to notice any differences in airspaces in lung parenchyma, it is possible to observe the thickening of airway walls (arrows). The analysis of airway wall thickness is presented in Figure 5. ROFA = residual oil fly ash. 

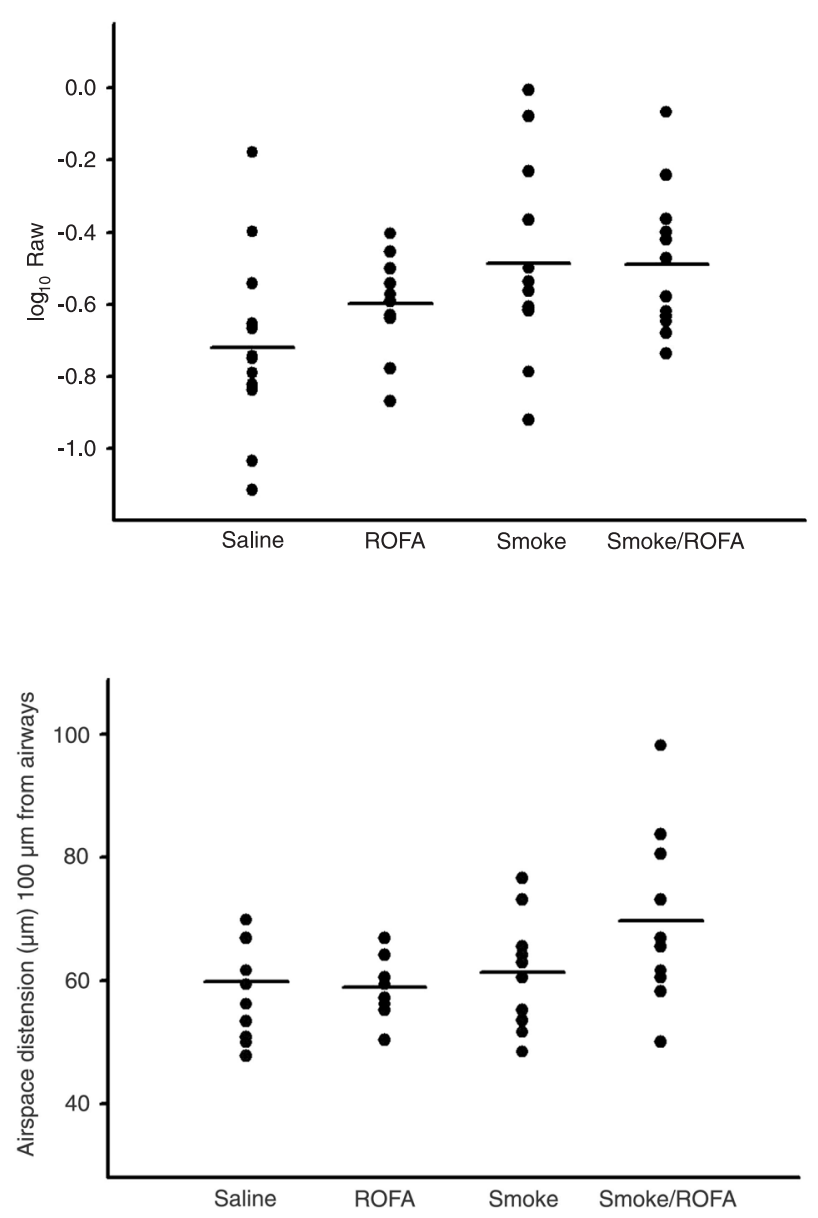

Figure 3. Airway resistance (Raw). Measurements were made according to Hantos et al. (24). Dots represent individual values and horizontal lines indicate the group mean. There was an increase in Raw associated with the smoke factor $(P=0.01$ for the smoke factor, two-way ANOVA). There were no statistically significant differences among groups in the measurements of tissue damping (Gtis) and tissue elastance (Htis). ROFA = residual oil fly ash.

Figure 4. Airspace distension. Airspace sizes were measured at different distances from the terminal bronchiole in all 48 animals. Using a frame with 5 semicircles and the same center, we measured airspace distension at 5 different distances from the airways (see Methods for details), that are represented in the graphs. The horizontal lines represent the group mean. We observed an increase in mean airspace size at $100 \mu \mathrm{m}$ from the airways in the animals exposed to smoke $(P=0.034$ for the smoke factor, two-way ANOVA). There was also an increase in airspaces at $150 \mu \mathrm{m}$ from the airways in the animals exposed to ROFA ( $P=0.006$ for the ROFA factor, two-way ANOVA). There were no statistically significant differences between groups at 50,200 , and $250 \mu \mathrm{m}$ from airways. ROFA = residual oil fly ash.

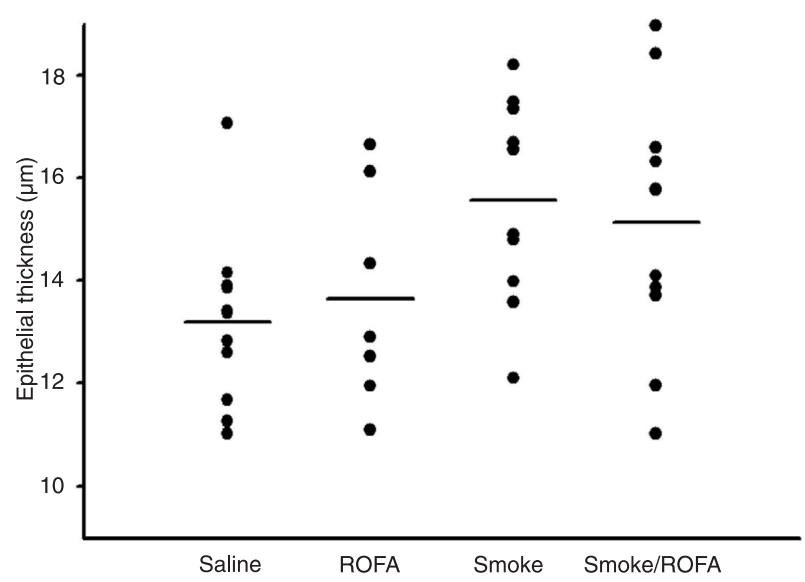

Figure 5. Airway wall thickness. Wall thickness was calculated by dividing the airway wall area by its length in photomicrographs obtained from 39 animals. Dots represent individual values of mean wall thickness. Horizontal lines indicate the group mean. There was an increase in mean airway wall thickness associated with the exposure to smoke ( $P=0.006$ for the smoke factor, twoway ANOVA). ROFA = residual oil fly ash. 

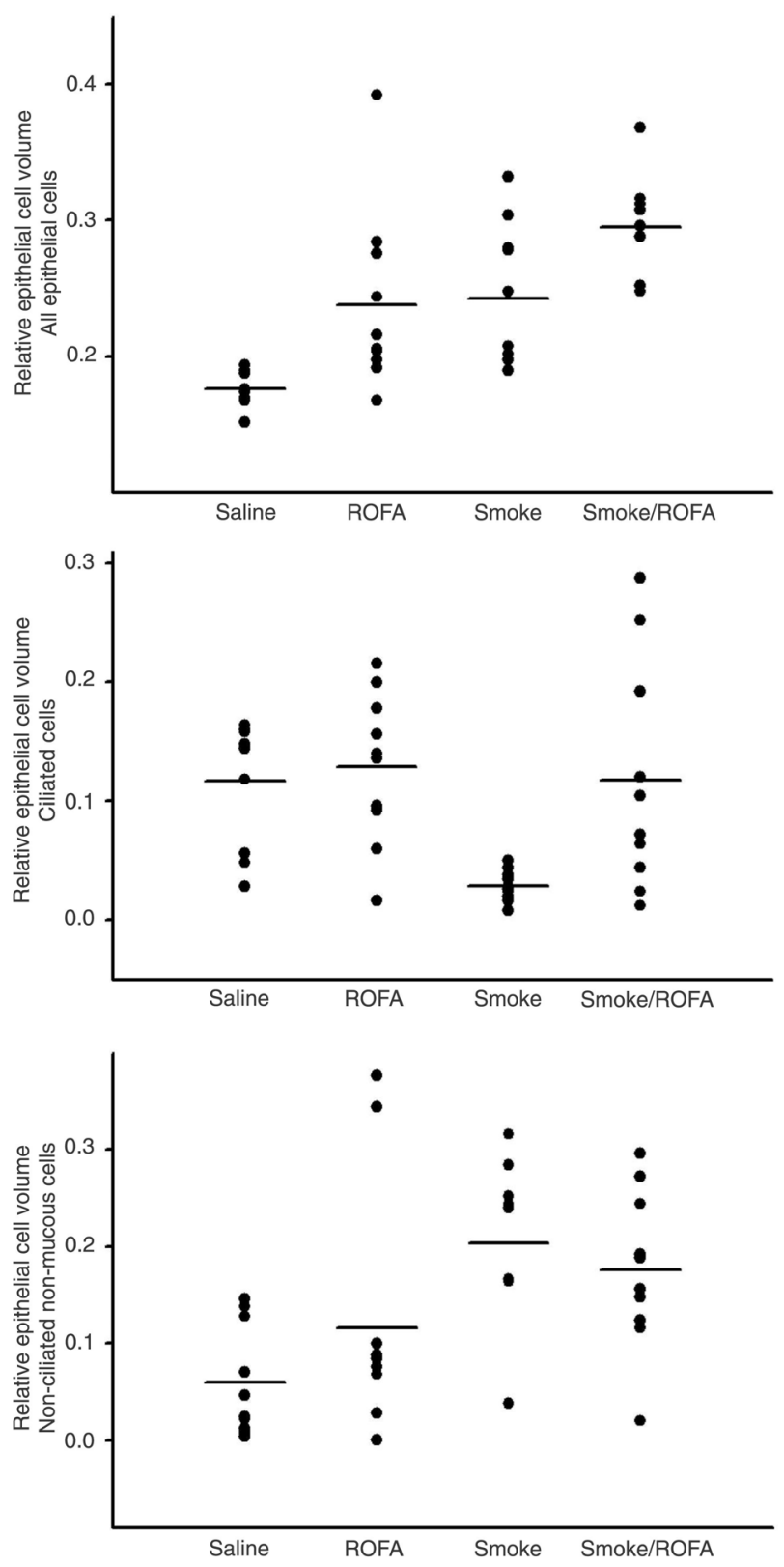

Figure 6. Relative epithelial cell volume in lung airways. Data were analyzed by point counting, which permitted us to estimate the area occupied by each type of cell in the epithelium. Points indicate individual values and horizontal lines represent the group median. Note that the data are non-parametric. We observed a change in the relative area occupied either by total epithelial cells $(P<0.001$, Kruskal-Wallis test) or by ciliated cells $(P=0.003$, Kruskal-Wallis test) and even by non-ciliated non-mucous cells $(P=0.003$, Krukal-Wallis test). There was an increase in the total epithelial cell area in all exposed groups: ROFA, Smoke and Smoke/ROFA. However, there was a marked decrease in the epithelial cell area in the group exposed only to smoke, which was to some extent attenuated by co-exposure to ROFA. All groups also showed an increase in the non-ciliated non-mucous cell area when compared to control animals. ROFA = residual oil fly ash.
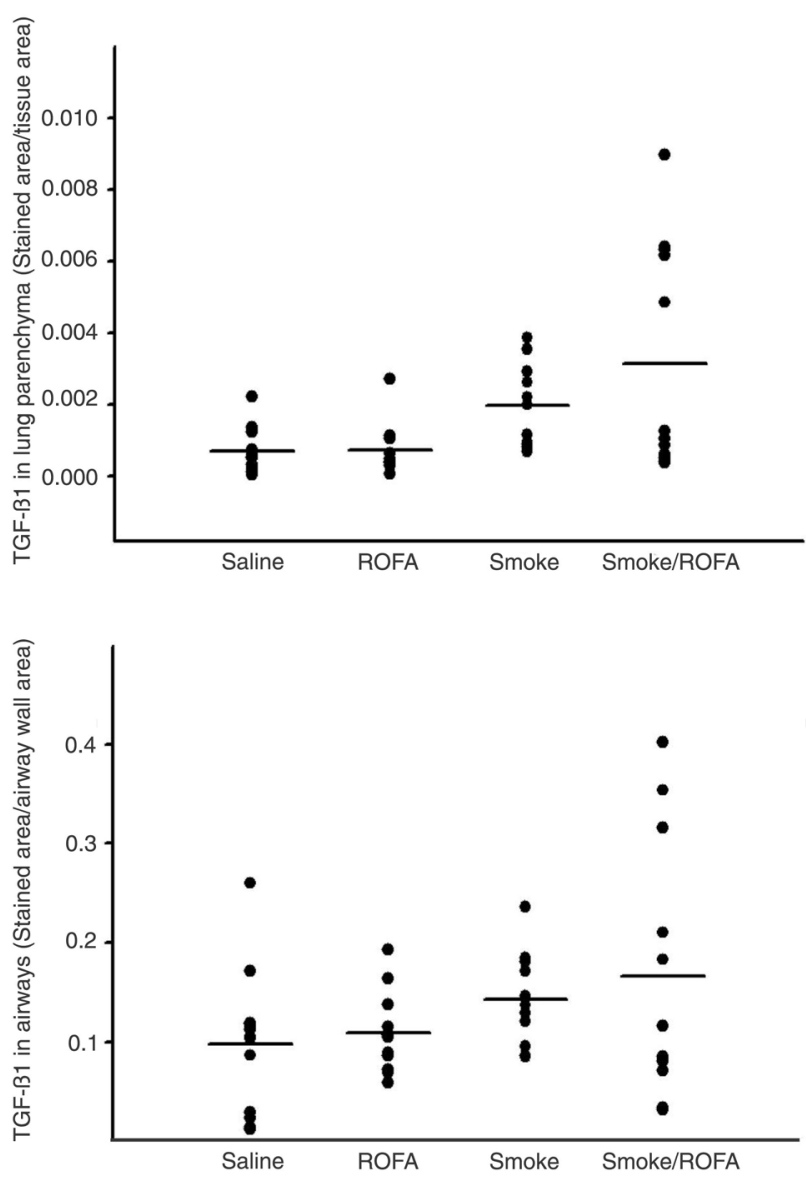

Figure 7. Transforming growth factor- $\beta 1$ (TGF- $\beta 1$ ) in lung airways and lung parenchyma. Data were obtained by immunohistochemistry, by determining the area stained for TGF- $\beta 1$ and dividing it by the parenchyma or airway area in photomicrographs obtained from 47 animals. Dots represent individual values of stained area corrected for parenchyma area. Horizontal lines indicate the group mean. There was an increase in the TGF- $\beta 1$ staining in the airways $(P=0.032$ for the smoke factor, two-way ANOVA) and also in lung parenchyma $(P=0.001$ for the smoke factor, two-way ANOVA). ROFA = residual oil fly ash.

epithelium of these airways (Figure 6) showed a change in the profile of the cells lining this region, i.e., all epithelial cells ( $P$ $<0.001)$, ciliated epithelial cells $(P=0.003)$ and non-ciliated, non-mucous cells $(P=0.003)$. There was an increase in the proportion of the area occupied by all epithelial cells in animals exposed to ROFA and/or smoke. This increase was accompanied by a decrease in the area of ciliated cells in the group exposed to smoke and an increase in the area of non-ciliated non-mucous cells in this group of animals. The groups exposed to ROFA and to both ROFA and smoke did not present the decrease in ciliated cell area observed in the Smoke group, but also showed an increase in the area of non-ciliated non-mucous cells. 
Figure 7 shows the results of TGF- $\beta 1$ staining in the airways and lung parenchyma. Examples of photomicrographs of a slide stained for TGF- $\beta 1$ are shown in Figure 2. We noted an increase in the stained area corrected by airway or tissue area in the groups exposed to smoke. These increases were observed in both the airways (twoway ANOVA, $P=0.032$ for the factor smoke) and in lung parenchyma (two-way ANOVA, $\mathrm{P}=0.001$ for the factor smoke).

\section{Discussion}

In the present study, we assessed in mice the pulmonary effects of exposure to cigarette smoke and ROFA for 2 months. We observed an increase in airway resistance accompanied by an increase in airway wall thickness and epithelial cell area, although we did not detect any inflammatory reaction or collagen and elastic fiber remodeling. We also observed a localized enlargement of airspaces near the terminal bronchioles, and an increase in TGF- $\beta 1$ production in the airways and lung parenchyma.

\section{Emphysema}

There are many different established mouse models of emphysema. In most of them, at least 6 months of cigarette smoke exposure are required for the animals to develop enlargement of the airspaces $(6,7,14-17)$. Shorter exposures can produce emphysema in animals with very low levels of a1-antitrypsin (17), and the species susceptibility to smoke exposure may be determined by the levels of this enzyme (16). C57/BL6, the mouse species used in the present study, is moderately sensitive to the development of emphysema after smoke exposure (25).

In the present study, after two months of exposure to cigarette smoke and/or ROFA, the animals developed an airspace enlargement that was not widespread throughout the lungs. The enlargements were limited to the regions located 100 to $150 \mu \mathrm{m}$ from terminal bronchioles. The method to measure airspace enlargement may explain why it was possible to detect these enlargements at an earlier phase of disease progression. Since the airspace sizes were measured in different lung regions, with respect to their distances from terminal bronchioles, it was possible to detect smaller increases. These differences were not detected when we obtained a single value of airspace distension, mean linear intercept, for the whole lung (data not shown). The heterogeneity of lung lesions and the incipient stage of airspace enlargement may also explain the lack of reduction in Htis. Since alveolar distension only appeared in limited areas within the lungs, measurement of lung mechanics were not sensitive enough to detect these small space enlargements.

In 2004, Valença et al. (26) published a model of emphysema formation in C57/BL6 mice after only 2 months of smoke exposure. In their model, mice were exposed to cigarette smoke 7 days a week, three times a day, and had increased airspaces and inflammatory reactions at the end of the protocol. Some differences between this model and ours could explain the apparently conflicting results. Exposure for two additional days per week and the repeated exposures per day may have accounted for the differences. It is possible that shortening the time between exposures may damage lung repair mechanisms. In this respect, the frequency of smoke exposure could be more important to determine emphysema formation than the dose of smoke exposure.

The results of the present study indicate the heterogeneity of the emphysematous lesions and provide experimental evidence for the predominance of airspace enlargements in the lung areas surrounding the airways, as described in human COPD. Proximal lung regions may have a higher turnover rate, or may have a matrix less resistant to protease attack. Different experimental designs will be needed to address these questions.

\section{Inflammatory reaction}

We were not able to detect any inflammatory reaction in animals exposed either to ROFA or to smoke. However, inflammatory reaction is believed to play a central role in COPD development (27-30). Besides, experimental research has already shown the requirement of neutrophils and macrophages for disease development $(6,7)$.

Some investigators have evaluated the response of inflammatory cells and cytokine production soon after smoke exposure $(18,19)$. This immediate response, however, fades over time, and a change in the biological response pattern during disease development has been shown in mouse models $(18,20)$ as well as in human COPD (31). In some other models, inflammatory reaction was also not found, or inflammatory response had been impaired by smoke exposure $(32,33)$.

The relatively short-time protocol used in the present study allowed us to evaluate emphysema at an early stage. While there is a very incipient change in lung parenchyma, detected by the localized airspace enlargements, the inflammatory cells were not increased in this region. Although these data cannot rule out the importance of the inflammatory reaction for the perceived emphysematous lesions, they could suggest that alternative mechanisms are acting in the emphysema progression.

Many studies have been published evaluating the role of apoptosis, growth factors and other mediators, antioxidants, and defects on lung repair mechanisms leading to emphysema formation (9-12,34-37). These alternative pathways may in fact be coordinated by the inflammatory cells, but they may also have an independent role and could be the trigger for the chronic inflammatory reaction usually observed in COPD patients.

\section{Epithelial cells}

Besides the increase in airspaces in limited lung regions, 
we observed an increase in Raw, thickening of airway walls, and a change in the profile of epithelial cells. Epithelium may have an important role in emphysema development and in regulation of oxidative stress induced by smoke (38).

The thickening of the airway walls and the increase in Raw are physiologically compatible and are hallmarks of one pole of COPD, i.e., chronic bronchitis. Indeed, many patients develop chronic cough, reduction in forced expiratory volume in 1 second (FEV1) and increased airway resistance. Many of these patients also complain of sputum production, which was not noticed in our animals (data not shown). The absence of sputum and mucous secretion is probably a limitation of the mouse model since these animals have few submucosal glands eliciting little mucous production (39).

In our animals, we observed an increase in the area occupied by epithelial cells, although the features of these cells changed. Exposure to smoke produced a dramatic decrease in the ciliated cell area, which was replaced by non-mucous non-ciliated cells. Despite the decrease in ciliated cell area, the total area of epithelial cells was increased.

Nevertheless, in the animals exposed to ROFA, the increase in total cell area was smaller, and there was no decrease in ciliated cell area. Animals exposed to ROFA and smoke had a decrease in the ciliated cell area, but to a lesser extent than the animals exposed only to smoke.

These differences suggest that the two noxious stimuli are handled in different ways by epithelial cells, leading to unequal responses. The combination of the two toxins in the human disease may cause enhancement of symptoms by combining two independent biological responses.

While the parenchyma lesion was minimal, the airways' changes were far more significant. Due to the fact that these animals had been exposed to a period of time that was not long enough to produce widespread emphysema, but

\section{References}

1. GOLD (Global Initiative for Chronic Obstructive Lung Disease). Global strategy for the diagnosis, management and prevention of COPD. 2010. Available at [http://www. goldcopd.org].

2. Anderson HR, Spix C, Medina S, Schouten JP, Castellsague $\mathrm{J}$, Rossi G, et al. Air pollution and daily admissions for chronic obstructive pulmonary disease in 6 European cities: results from the APHEA project. Eur Respir J 1997; 10: 1064-1071.

3. Yang Q, Chen Y, Krewski D, Burnett RT, Shi Y, McGrail KM. Effect of short-term exposure to low levels of gaseous pollutants on chronic obstructive pulmonary disease hospitalizations. Environ Res 2005; 99: 99-105.

4. Lopes FD, Pinto TS, Arantes-Costa FM, Moriya H, Biselli PJ, Ferraz LF, et al. Exposure to ambient levels of particles emitted by traffic worsens emphysema in mice. Environ Res 2009; 109: 544-551.

5. Barnes PJ, Shapiro SD, Pauwels RA. Chronic obstructive that was longer than the period eliciting only acute phase responses, we suggest that this model may represent the initial phases of the chronic lung response. At this stage of the disease, we noticed that the parenchyma lesion had just started. However, epithelial responses were already easily detectable and we speculate that the epithelial cells may trigger the initial responses of the whole chain of events that will develop in the lung if toxin exposure continues.

We also detected an increase in the production of TGF- $\beta 1$ in the airways and lung parenchyma. TGF- $\beta 1$ is a growth factor involved in signaling for cell proliferation and collagen fiber deposition (40). TGF- $\beta 1$ production by epithelial cells may be one of the signals for the increase in epithelial cell area and will possibly be the stimulus for collagen fiber deposition in lung parenchyma. Since fiber increase could not be detected, it seems that remodeling had not started at this stage of the disease. Yet, the stimulus for this process was apparently already present.

We suggest that in a chronic, but short-term, toxin exposure mouse model epithelial cells may be signaling the ongoing presence of cigarette smoke or pollution to the lung parenchyma and other lung structures. The pathways used for this communication are not completely known, but TGF- $\beta 1$ may be one of the molecules involved in this signaling.

\section{Acknowledgments}

We thank Maria Cristina Medeiros and Angela dos Santos Batista, from Laboratório de Poluição Atmosférica (LIM 5), Departamento de Patologia, Faculdade de Medicina, Universidade de São Paulo, São Paulo, SP, Brazil, for the careful immunohistochemical preparations, which were essential for the conclusion of the present study. Research supported by FAPESP, CNPq, and FFM (Fundação Faculdade de Medicina). pulmonary disease: molecular and cellular mechanisms. Eur Respir J 2003; 22: 672-688.

6. Hautamaki RD, Kobayashi DK, Senior RM, Shapiro SD. Requirement for macrophage elastase for cigarette smoke-induced emphysema in mice. Science 1997; 277: 2002-2004.

7. Shapiro SD, Goldstein NM, Houghton AM, Kobayashi DK, Kelley D, Belaaouaj A. Neutrophil elastase contributes to cigarette smoke-induced emphysema in mice. Am J Pathol 2003; 163: 2329-2335.

8. MacNee W. Oxidants/antioxidants and COPD. Chest 2000; 117: 303S-317S.

9. Demedts IK, Demoor T, Bracke KR, Joos GF, Brusselle GG. Role of apoptosis in the pathogenesis of COPD and pulmonary emphysema. Respir Res 2006; 7: 53.

10. Henson PM, Vandivier RW, Douglas IS. Cell death, remodeling, and repair in chronic obstructive pulmonary disease? Proc Am Thorac Soc 2006; 3: 713-717.

11. Rennard SI, Togo S, Holz O. Cigarette smoke inhibits alveo- 
lar repair: a mechanism for the development of emphysema. Proc Am Thorac Soc 2006; 3: 703-708.

12. Kasahara Y, Tuder RM, Taraseviciene-Stewart L, Le Cras TD, Abman S, Hirth PK, et al. Inhibition of VEGF receptors causes lung cell apoptosis and emphysema. $J$ Clin Invest 2000; 106: 1311-1319.

13. Tuder RM, Zhen L, Cho CY, Taraseviciene-Stewart L, Kasahara $Y$, Salvemini D, et al. Oxidative stress and apoptosis interact and cause emphysema due to vascular endothelial growth factor receptor blockade. Am J Respir Cell Mol Biol 2003; 29: 88-97.

14. Cavarra E, Bartalesi B, Lucattelli M, Fineschi S, Lunghi B, Gambelli F, et al. Effects of cigarette smoke in mice with different levels of alpha(1)-proteinase inhibitor and sensitivity to oxidants. Am J Respir Crit Care Med 2001; 164: 886-890.

15. Foronjy RF, Mirochnitchenko O, Propokenko O, Lemaitre $\mathrm{V}$, Jia $\mathrm{Y}$, Inouye $\mathrm{M}$, et al. Superoxide dismutase expression attenuates cigarette smoke- or elastase-generated emphysema in mice. Am J Respir Crit Care Med 2006; 173: 623631.

16. Guerassimov A, Hoshino Y, Takubo Y, Turcotte A, Yamamoto $\mathrm{M}$, Ghezzo H, et al. The development of emphysema in cigarette smoke-exposed mice is strain dependent. Am J Respir Crit Care Med 2004; 170: 974-980.

17. Takubo Y, Guerassimov A, Ghezzo H, Triantafillopoulos A, Bates JH, Hoidal JR, et al. Alpha1-antitrypsin determines the pattern of emphysema and function in tobacco smokeexposed mice: parallels with human disease. Am J Respir Crit Care Med 2002; 166: 1596-1603.

18. Churg A, Tai H, Coulthard T, Wang R, Wright JL. Cigarette smoke drives small airway remodeling by induction of growth factors in the airway wall. Am J Respir Crit Care Med 2006; 174: 1327-1334.

19. Churg A, Zay K, Shay S, Xie C, Shapiro SD, Hendricks $\mathrm{R}$, et al. Acute cigarette smoke-induced connective tissue breakdown requires both neutrophils and macrophage metalloelastase in mice. Am J Respir Cell Mol Biol 2002; 27: 368-374.

20. Wan WY, Morris A, Kinnear G, Pearce W, Mok J, Wyss D, et al. Pharmacological characterization of anti-inflammatory compounds in acute and chronic mouse models of cigarette smoke-induced inflammation. Respir Res 2010; 11: 126135.

21. Arantes-Costa FM, Lopes FD, Toledo AC, Magliarelli-Filho PA, Moriya HT, Carvalho-Oliveira R, et al. Effects of residual oil fly ash (ROFA) in mice with chronic allergic pulmonary inflammation. Toxicol Pathol 2008; 36: 680-686.

22. Ghio AJ, Silbajoris R, Carson JL, Samet JM. Biologic effects of oil fly ash. Environ Health Perspect 2002; 110 (Suppl 1): 89-94.

23. Institute of Laboratory Animal Resources. Commission on Life Science. National Research Council. Guide for the care and use of laboratory animals. Washington: National Academy Press; 1996.

24. Hantos Z, Daroczy B, Suki B, Nagy S, Fredberg JJ. Input impedance and peripheral inhomogeneity of dog lungs. $J$ Appl Physiol 1992; 72: 168-178.

25. Yao H, Edirisinghe I, Rajendrasozhan S, Yang SR, Caito S, Adenuga $\mathrm{S}$, et al. Cigarette-smoke mediated inflammatory and oxidative responses are strain-dependent in mice. Am J Physiol Lung Cell Mole Physiol 2008; 294: L-1174-L-1186.

26. Valenca SS, da Hora K, Castro P, Moraes VG, Carvalho
L, Porto LC. Emphysema and metalloelastase expression in mouse lung induced by cigarette smoke. Toxicol Pathol 2004; 32: 351-356.

27. Di Stefano A, Capelli A, Lusuardi M, Balbo P, Vecchio C, Maestrelli $P$, et al. Severity of airflow limitation is associated with severity of airway inflammation in smokers. Am J Respir Crit Care Med 1998; 158: 1277-1285.

28. Di Stefano A, Turato G, Maestrelli P, Mapp CE, Ruggieri MP, Roggeri A, et al. Airflow limitation in chronic bronchitis is associated with T-lymphocyte and macrophage infiltration of the bronchial mucosa. Am J Respir Crit Care Med 1996; 153: 629-632.

29. Saetta M, Di Stefano A, Maestrelli P, Ferraresso A, Drigo R, Potena A, et al. Activated T-lymphocytes and macrophages in bronchial mucosa of subjects with chronic bronchitis. Am Rev Respir Dis 1993; 147: 301-306.

30. Saetta M, Turato G, Facchini FM, Corbino L, Lucchini RE, Casoni G, et al. Inflammatory cells in the bronchial glands of smokers with chronic bronchitis. Am J Respir Crit Care Med 1997; 156: 1633-1639.

31. Di Stefano A, Caramori G, Ricciardolo FL, Capelli A, Adcock IM, Donner CF. Cellular and molecular mechanisms in chronic obstructive pulmonary disease: an overview. Clin Exp Allergy 2004; 34: 1156-1167.

32. Brandsma CA, Hylkema MN, Luinge MA, Geerlings M, Klok PA, Cassee FR, et al. Nitrogen dioxide exposure attenuates cigarette smoke-induced cytokine production in mice. Inhal Toxicol 2008; 20: 183-189.

33. Gaschler GJ, Zavitz CC, Bauer CM, Skrtic M, Lindahl M, Robbins CS, et al. Cigarette smoke exposure attenuates cytokine production by mouse alveolar macrophages. Am J Respir Cell Mol Biol 2008; 38: 218-226.

34. Wang RD, Wright JL, Churg A. Transforming growth factorbeta1 drives airway remodeling in cigarette smoke-exposed tracheal explants. Am J Respir Cell Mol Biol 2005; 33: 387393.

35. Chen ZH, Lam HC, Jin Y, Kim HP, Cao J, Lee SJ, et al. Autophagy protein microtubule-associated protein 1 light chain-3B (LC3B) activates extrinsic apoptosis during cigarette smoke-induced emphysema. Proc Natl Acad Sci USA 2010; 107: 18880-18885.

36. Yao H, Arunachalam G, Hwang JW, Chung S, Sundar IK, Kinnula VL, et al. Extracellular superoxide dismutase protects against pulmonary emphysema by attenuating oxidative fragmentation of ECM. Proc Natl Acad Sci USA 2010; 107: 15571-15576.

37. Rangasamy T, Misra V, Zhen L, Tankersley CG, Tuder RM, Biswal S. Cigarette smoke-induced emphysema in A/J mice is associated with pulmonary oxidative stress, apoptosis of lung cells, and global alterations in gene expression. $A m \mathrm{~J}$ Physiol Lung Cell Mol Physiol 2009; 296: L-888-L-900.

38. Adair-Kirk TL, Atkinson JJ, Griffin GL, Watson MA, Kelley DG, DeMello D, et al. Distal airways in mice exposed to cigarette smoke: Nrf2-regulated genes are increased in Clara cells. Am J Respir Cell Mol Biol 2008; 39: 400-411.

39. Mahadeva R, Shapiro SD. Chronic obstructive pulmonary disease * 3 : Experimental animal models of pulmonary emphysema. Thorax 2002; 57: 908-914.

40. Klass BR, Grobbelaar AO, Rolfe KJ. Transforming growth factor beta1 signalling, wound healing and repair: a multifunctional cytokine with clinical implications for wound repair, a delicate balance. Postgrad Med J 2009; 85: 9-14. 